\title{
Agregação de valor nos produtos da agricultura familiar de Foz do Iguaçu -PR: $O$ caso da agroindústria Delicias do Campo
}

\author{
Agregación de valor en los productos de la agricultura familiar de Foz do \\ Iguaçu -PR: El caso de la agroindustria Delicias del Campo
}

\section{Aggregation of value in the products of the family agriculture of Foz do Iguaçu -PR: The case of the agroindustry Delicias do Campo}

Rafael Lucas Alves Ferreira ${ }^{1}$

\begin{abstract}
Resumo
Este trabalho se propõem analisar a temática da agroindustrialização da produção agropecuária no espaço rural pela agricultura familiar. Referindo-se a uma atividade que permite o fortalecimento da agricultura familiar, possibilitando maneiras alternativas para o acesso aos mercados e para a comercialização dos seus produtos. Em relação aos procedimentos metodológicos realizou-se entrevistas semiestruturadas aplicadas a 4 agriculturas associadas a agroindústria familiar Delícias do Campo de Foz do Iguaçu. O estudo mostrou que a agroindustrialização atua como um papel estratégico no fortalecimento da agricultura familiar, sobretudo no desenvolvimento local.
\end{abstract}

Palavras-Chave: agroindústria; agricultura familiar

\section{Resumen}

Este trabajo se porpone analizar la temática de la agro-industrialización de la producción agropecuaria en el espacio rural por la agricultura familiar. En referencia a una actividad que permite el fortalecimiento de la agricultura familiar, proporcionando formas alternativas de acceso al mercado y la comercialización de sus productos. En relación a los procedimientos metodológicos se realizó entrevistas semi-estructuradas a 4 agriculturas asociadas a la agroindustria família Delicias Campo de Foz do Iguaçu. El estudio mostró que la agro-industrialización actúa como un papel estratégico en el fortalecimiento de la agricultura familiar, sobre todo en el desarrollo local.

Palabras claves: agroindustria; agricultura familiar.

\section{Abstract}

This work intends to analyze the thematic of the agroindustrialization of the agricultural production in the rural space by the familiar agriculture. Referring to an activity that allows the strengthening of family farming, allowing alternative ways to access markets and to market their products. Regarding the methodological procedures, semi-structured interviews were applied to four agriculturists associated with the agroindustry family delights of the Field of Foz do Iguaçu. The study showed that agroindustrialization acts as a strategic role in strengthening family agriculture, especially in local development.

Keywords: agroindustry; family farmers.

\footnotetext{
${ }^{1}$ Mestrando em Desenvolvimento Rural Sustentável; Universidade Estadual do Oeste do Paraná; Foz do Iguaçu, Paraná, Brasil; rafaeldrsa@gmail.com. Trabalho apresentado no I Seminário Latino-Americano de Estudos em Cultura - SEMLACult, Foz do Iguaçu/PR, Brasil, 2017.
} 


\section{Introdução}

O município de Foz do Iguaçu está situado no extremo oeste do Paraná, fazendo fronteira com outros dois países (Argentina e Paraguai). Com base no plano diretor do município, a área total corresponde a $617,71 \mathrm{~km}^{2}$ com uma área urbana de $191,46 \mathrm{~km}^{2}(31 \%$ do total) e com a área rural de $138,17 \mathrm{~km}^{2}(22,37 \%)$. O restante da área é dividido entre o parque nacional, que representa $22,44 \%$ da área total, e o lago de Itaipu, que conta com $24,14 \%$ da área total do município. A área rural de Foz do Iguaçu representa 22,37\% da superfície total do município, o que pode indicar que a atividade agropecuária não possua destaque acentuado na economia, ainda mais se confrontado com o fato do município ser marcado pelo turismo, no entanto temos o fato que a agricultura familiar representa um importante papel na produção de produtos agropecuários e matérias primas para a população brasileira. De acordo com os dados do último censo agropecuário realizado pelo IBGE, ela corresponde a $70 \%$ da produção de alimentos no Brasil, e representa 75 da mão de obra trabalhadora no espaço rural, apresentando formas distintas de organização, produção e comercialização que vão além da lógica puramente econômica.

A agroindústria familiar assume uma enorme relevância no espaço rural, pois se caracteriza como uma estratégia que permite agregar valor aos produtos agropecuários, promovendo impactos sociais e econômicos no contexto local da produção familiar. Paralelamente, estes empreendimentos possuem um papel estratégico para pensar a reprodução da agricultura familiar, pelo seu caráter diferenciado no acesso aos mercados, que ocorre por maneiras alternativas e não pelo modo tradicional como na produção de commodities. Além do mais, a valorização do produto artesanal rural cria um cenário favorável para comercialização dos produtos da agricultura familiar, os quais passam ser valorizados pelos consumidores que demandam por produtos com características especificas, como orgânicos, locais, artesanais etc (WILKINSON, 2008).

Esta pesquisa foi desenvolvida no município de Foz do Iguaçu e teve como temática o universo diverso e complexo da agricultura familiar com foco na agroindústria familiar. Para o levantamento de dados da pesquisa de campo foi selecionada uma agroindústria familiar que tivesse um perfil comunitário no espaço rural de Foz do Iguaçu. Com esse enfoque, selecionou-se a agroindústria familiar rural Delicias do Campo, onde foram realizadas entrevistas com quatro agricultoras familiares associadas a este empreendimento no período de 04 a 06 de maio de 2015. Para coletar os dados, foi utilizado um questionário com roteiro 
semiestruturado, onde havia perguntas fechadas, as quais as entrevistadas deveriam escolher uma das opções diretas solicitadas; e perguntas abertas, que oferecem ao entrevistado maior liberdade e espontaneidade nas respostas.

A relevância deste estudo ocorre pela necessidade de dar maior atenção aos incentivos prestados aos pequenos produtores em agregar valor a seus produtos, estimulando iniciativas de elaboração ou de processamento e comercialização da produção, tendo como foco a agroindustrialização, o que promove uma diversificação da oferta de alimentos à população, produzidos de maneiras sustentáveis.

\section{Agroindústria e agregação de valor}

Wilkinson (2008) afirma que a agroindústria familiar surge de um processo de "reconversão" para mercados artesanais devido ao contexto de exclusão dos agricultores familiares nos mercados agroindustriais. Vale ressaltar que as agroindústrias familiares também contribuem para diminuir o desemprego, a pobreza rural e, sobretudo o êxodo rural, que vem afetando diretamente a permanência dos agricultores no campo.

Desta forma, as agroindústrias familiares irão propiciar aos agricultores transformações benéficas em suas rendas aumentando a motivação de se viver no campo, diminuindo assim o êxodo rural e fomentando processos de desenvolvimento local. Portanto, a agroindustrialização da produção e a agregação de valor de seus produtos são uma alternativa rentável de geração de renda para os produtores rurais. $\mathrm{O}$ caráter artesanal que é conferindo aos produtos da agroindústria familiar representa o diferencial em relação às grandes agroindústrias (WESZ, 2008). A relação de proximidade entre produtor e consumidor é uma das características principais para diferenciar as agroindústrias familiares do modelo convencional. Mior (2007) complementa apontando que os agricultores estabelecem trajetórias distintas de acordo com o local em que estão inseridos, diferentemente das cadeias convencionais.

Pensando em um modelo de agro industrialização tendo como base contextos locais, é visto que a uma redução de uma série de custos, sobretudo o custo de transportes dada pela proximidade de matérias primas a estrutura das agroindústrias, a qual irá valorizar os aspectos locais relacionado à cultura da atividade de agro industrialização (PREZOTTO, 2000). A valorização dos produtos da agricultura familiar e consequente valorização de um determinado local, leva ao entendimento que o território e seus recursos locais é um 
importante fator para buscar o desenvolvimento territorial sustentável, não apenas por seus aspectos temporais e setoriais (ABRAMOVAY, 2003).

É notório perceber que a agregação de valor é uma das principais estratégias de inserção dos agricultores no mercado, sobretudo uma maneira de aumentar a rentabilidade das famílias. Como vários autores já constataram em seus estudos (WILKINSON, 2008), (MIOR 2007), (WESZ 2008) etc.

Importante perceber neste contexto, conforme já foi discutido que a utilização dos recursos locais, atua como uma estratégia para agregar valor nos produtos, uma vez que permite uma maior diversidade de produtos a serem oferecidos no mercado. Para Maluf (2004, p. 310), a valorização de produtos com atributos diferenciados de qualidade cria novas oportunidades de mercado, muitas das quais acessíveis aos agricultores de pequeno e médio porte, apontando que essas novas oportunidades incluem desde a inserção desses agricultores em mercados de nichos nacionais e internacionais até o aprimoramento dos circuitos regionais de produção.

\subsection{Estudo de caso da agroindústria familiar Delicias do Campo em Foz do Iguaçu- PR}

A agroindústria familiar "Delicias do Campo" (Figura 1), está localizado na comunidade Vasco da Gama, área rural do município de Foz do Iguaçu, e é associada à Cooperativa da Agricultura Familiar e Solidaria da Região Oeste do Paraná (COAFASO). Segundo as entrevistadas, as atividades de processamento iniciaram há três anos (2012), quando elas começaram a pensar em alguma alternativa que oportunizaria aumentar a renda familiar e a consequente melhora nas condições de vida das famílias.

Como a maioria das mulheres na comunidade produziam informalmente em suas casas pães, cucas e bolachas, tiveram a ideia de se unir e produzir seus produtos no mesmo locar, em uma única casa. A maioria das receitas é familiar, repassadas de geração em geração, onde as mulheres mais novas aprendem as receitas com as mais velhas. A venda dos produtos era realizada, inicialmente, em suas casas, mas com apoio da prefeitura passou a ser realizada de porta em porta. 


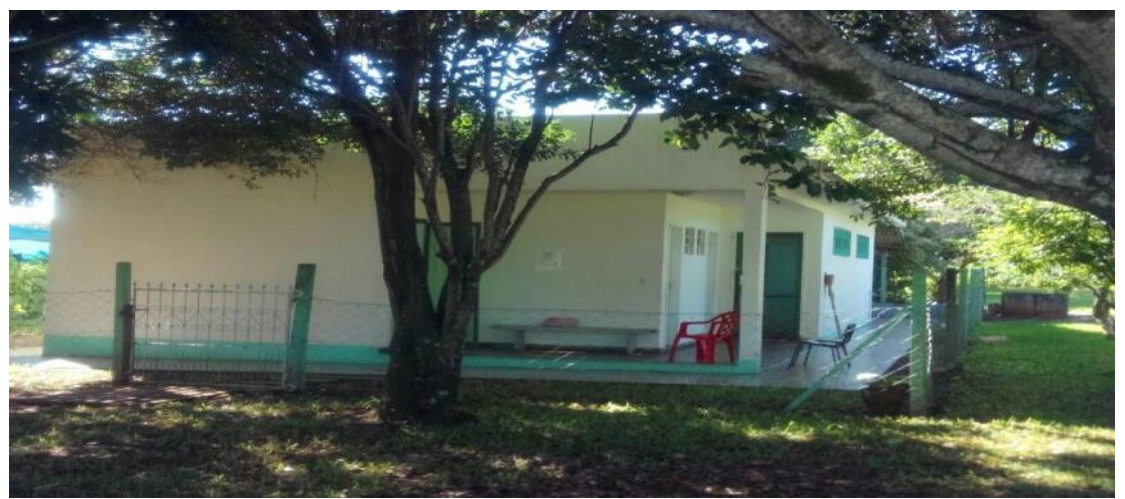

Figura 1 - Agroindústria familiar Delicias do Campo Fonte: Autor, 2015.

Com a produção coletiva de panificados e o aumento da demanda, as mulheres perceberam a necessidade da regularização da agroindústria junto às exigências sanitárias e fiscais. Buscaram apoio da prefeitura, onde receberam um terreno doado pela mesma e máquinas especializadas para a produção de panificados.

Atualmente a agroindústria possui 7 associados, sendo que a maioria das responsáveis pelas atividades são mulheres, que vivem na mesma comunidade e, antes da agroindústria, já estabeleciam relações de amizade. Instalada em um local ao lado da igreja da comunidade, o empreendimento possui as principais máquinas para o processamento dos produtos, as quais foram recentemente compradas com o próprio capital gerado pela venda dos panificados (substituindo os equipamentos disponibilizados pela prefeitura). A linha de produtos (Tabela 1) da agroindústria comunitária de panificação basicamente consiste em pães, cucas e bolachas. Além disso, quando há encomenda, produzem massas, bolos e salgados.

Tabela 1 - Linha de produtos, produção mensal e preço Agroindústria Delicias do Campo

\begin{tabular}{l|c|c}
\hline Produtos & $\begin{array}{c}\text { Produção } \\
\text { Mensal (Kg) }\end{array}$ & Preço de Venda \\
\hline Pão & 280 & 8,00 \\
Branco & & 11,00 \\
\hline Pão & 200 & 11,00 \\
Integral & & \\
\hline Cuca & 280 & 11,00 \\
\hline Bolachas & 50 & \\
\hline
\end{tabular}

Fonte: Pesquisa de campo, 2015. 
Farinha de trigo, farinha de milho, leite, ovos, manteiga, sal, açúcar, fermento, entre outros, são os principais produtos e matérias primas usadas pela agroindústria. Segundo as entrevistadas, alguns produtos são adquiridos pelas associadas em suas propriedades - como o leite e ovos - e os demais são comprados via fornecedores - como farinha, açúcar, fermento etc. Sobre a distribuição das atividades na agroindústria, todas conhecem e participam das etapas de produção, como preparar as massas, misturar, amassar, levar e retirar do forno, embalar e rotular os produtos. O veículo utilizado para venda dos produtos é conduzido por um dos membros da agroindústria, o qual fica responsável pelo transporte até os canais de comercialização.

Das quatro integrantes entrevistadas, três sempre desenvolveram atividades no espaço rural, como agricultoras familiares. A quarta entrevistada, que é a mais jovem, está menos tempo na atividade da agroindústria familiar, pois veio para comunidade recentemente acompanhada pelo marido. Com o aumento da produção na agroindústria, elas passaram a se dedicar a maior parte do dia nas atividades de produção agroindustrial, mas ainda ajudam nos afazeres de casa.

De acordo com as entrevistadas, a assistência técnica foi fundamental para a consolidação da atividade agroindustrial, pois passaram por uma série de capacitações, orientações técnicas e treinamentos especializados repassados pelo Instituto Paranaense de Assistência Técnica e Extensão Rural - EMATER. A gestão financeira da agroindústria é realizada por todos os membros e mensalmente ocorre uma reunião onde todos os associados participam e o lucro obtido pela comercialização dos produtos é dividido igualmente entre eles.

Os principais mercados que a agroindústria acessa são os institucionais, como Programa de Aquisição de Alimentos (PAA) e o Programa Nacional de Alimentação Escolar (PNAE), acessados a partir da COAFASO. Além disso, existem outros canais de comercialização, como a venda na própria propriedade, em feiras livres e em festas da comunidade. Segundo Vorley, Pozo-Vergnes y Barlett (2013), os mercados informais tradicionais estabelecem uma relação funcional entre agricultores e consumidores que responde as exigências do consumidor, não podendo ser considerado como uma falha de mercado. Por outro lado, os compradores formais reduzem os preços dos pequenos produtores e os supermercados exigem produtos de alta qualidade, mas nem sempre oferecem os melhores preços para eles. Mas a informalidade implica menos arrecadação tributária para 
o Estado, isso leva a menos incentivo há serviços rurais e inclusive menos incentivos para os agricultores pobres em se formalizar e ter acesso ao crédito e outros serviços para melhorar a sua produção e competitividade (VORLEY, POZO-VERGNES Y BARLETT, 2013).

Atualmente a agroindústria possui algumas dificuldades pontuais como: a falta de prateleiras para colocar os produtos; dificuldade na captação de recursos; elevado preço da matéria-prima, sobretudo da farinha, que às vezes reduz a rentabilidade da atividade. A atividade agroindustrial foi considerada, por todas as entrevistadas, fundamental para o aumento da qualidade de vida das famílias, permitindo um acréscimo na renda total da família, como pode ser observado na Tabela 2.

Tabela 2 - Aumento da renda liquida

\begin{tabular}{l|c}
\hline Membros & Aumento da renda \% \\
\hline Entrevista 1 & $30 \%$ \\
\hline Entrevista 2 & $70 \%$ \\
\hline Entrevista 3 & $50 \%$ \\
\hline Entrevista 4 & $20 \%$ \\
\hline
\end{tabular}

Fonte: Pesquisa de campo, 2015.

Para a entrevistada 1, houve um aumento de $30 \%$ na totalidade da renda da família, que permitiu pagar um serviço de internet para família. Já para a entrevistada 2, que é aposentada e vive sozinha, teve um aumento de $70 \%$ em sua renda, que utiliza para melhorar sua qualidade de vida e poder ajudar os filhos e netos. Para entrevistada 3, o lucro na agroindústria representa um peso de $50 \%$ na totalidade da renda da família, o qual é investido no conforto da família. Para a quarta entrevistada, a atividade representa $20 \%$ na renda total da família e permitiu melhoras na qualidade de vida da família, como a possibilidade de financiar um carro, o que facilita a locomoção até a cidade.

Nota-se que há uma diferença no peso da renda obtida pela agroindústria entre as famílias das entrevistadas, o que pode ser explicado por algumas terem outras fontes de rendas, como no caso de uma das mulheres que é aposentada, e também pela quantidade de membros de cada família. Na figura 2 pode-se perceber a relação entre a quantidade de membros de cada família e o peso da renda da agroindústria sobre a renda total. A entrevistada com o maior número de membros na família é que possui menor porcentagem na 
representatividade do peso na renda da família, quando comparada com as demais, o que pode ser explicado pelo fato de ter outras fontes de renda e deter mais gastos com alimentação, saúde e escola dos filhos. A que possui dois membros na família tem um peso de $50 \%$ do total da renda, enquanto a entrevistada com o maior peso da renda da agroindústria (70\%) vive sozinha na comunidade, tendo a maioria dos gastos individuais. A entrevistada com quatro membros na família tem um peso da renda da atividade agroindustrial de $30 \%$.

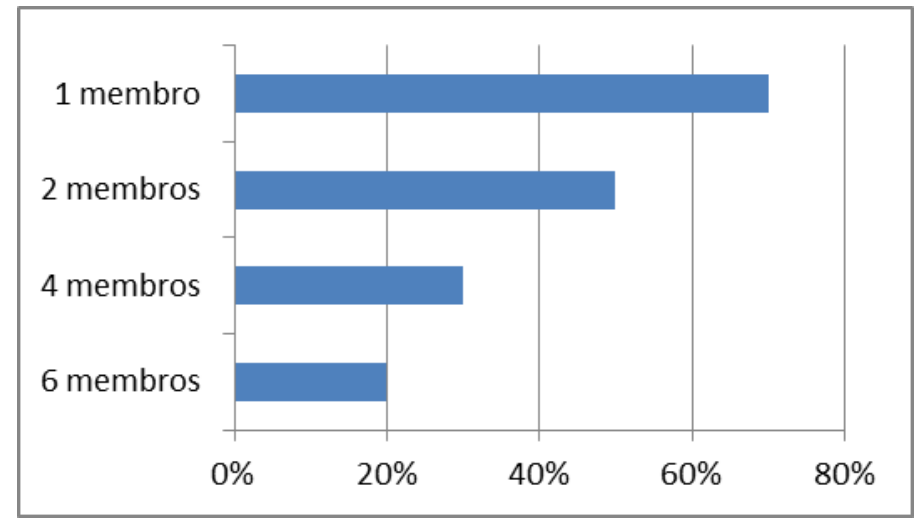

Figura 2 - Porcentagem da renda da agroindústria (sobre a renda total) por quantidade de membros na família

Fonte: Pesquisa de Campo, 2015.

No que diz respeito a aspectos de agregação de valor, quando perguntadas sobre o que consideram de diferencial nos produtos da agroindústria, a primeira entrevistada deu destaque sobre o fato das receitas serem caseiras e simples, sem muita adição de insumos químicos como sódio, corantes, etc. Outra chamou atenção ao fato de ser uma agroindústria comunitária, onde todas trabalham juntas. A terceira entrevistada apontou o aspecto da qualidade dos produtos, tratando-se de um alimento mais caseiro. Já a quarta entrevistada destacou o "saber fazer" das associadas e sua dedicação: "São produtos deliciosos feitos com muito amor e carinho e muito bem feitos" (OR)

Todos os produtos são embalados e rotulados com a logomarca, conhecida como Delícias do Campo. Existe um rótulo para cada produto da agroindústria (Figura 3). 


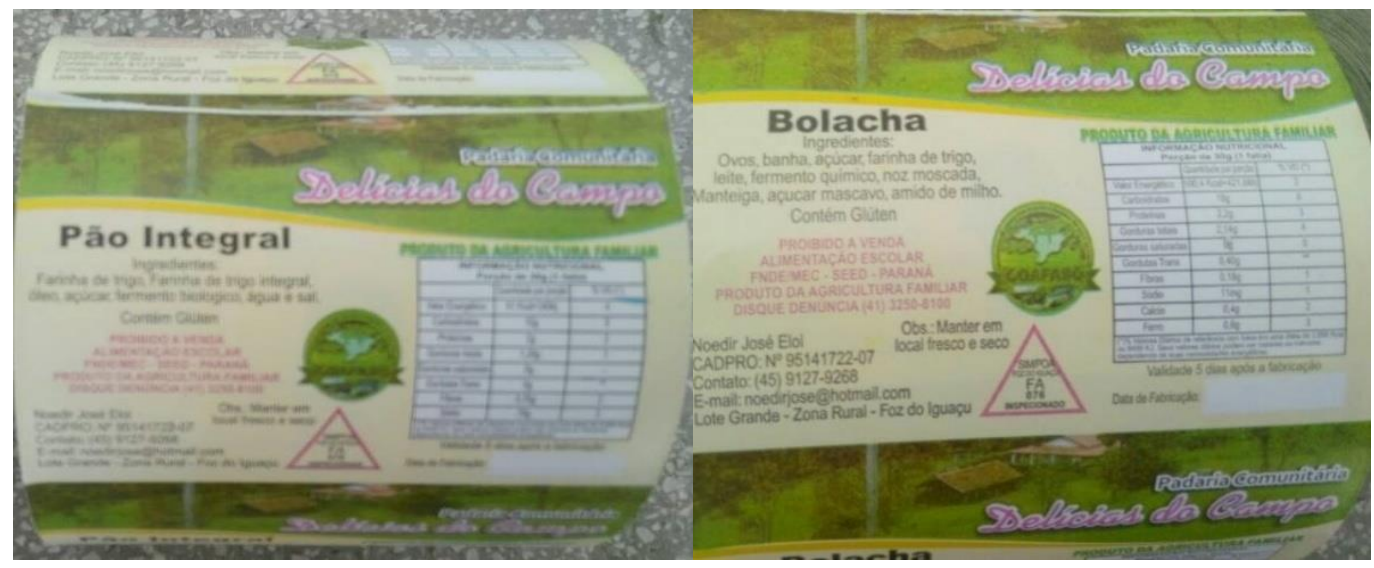

Figura 3 - Rotulagem dos produtos da agroindústria Fonte: Autor, 2015.

Quando questionadas em relação ao fato do consumidor adquirir seus produtos, o aspecto qualidade foi considerado por todas como o fator com maior grau de importância, seguidos pela busca de produtos naturais e pela valorização do produto rural, além do preço que segundo elas é mais acessível. A partir da pergunta foi possível conhecer um pouco das estratégias de agregação de valor da agroindústria, como o próprio nome Delicias do Campo, que evidencia a valorização do produto rural, chamando atenção do consumidor em relação ao resgate da vivência no espaço rural, do saber fazer das receitas que são repassadas por gerações nas famílias, agregando neste contexto valores simbólicos. Para este grupo de mulheres a valorização do produto rural e a busca por alimentos naturais criaram um ambiente favorável para o desenvolvimento da atividade de agroindustrialização, uma que vez que elas consideraram estes fatores como sendo os principais motivos pelos quais os consumidores buscam seus produtos.

A agroindústria comunitária Delícias do Campo possui uma produção pautada na economia solidária porque surgiu a partir da associação entre as mulheres com interesses e objetivos comuns. Mesmo inseridos dentro de um sistema agroalimentar tradicional, há o incentivo a revalorização da produção artesanal e caseira, incorporado às receitas tradicionais das famílias rurais num "novo produto" ao mercado. O sistema agroalimentar analisado traz a visão sistêmica e conjunta das atividades executadas dentro do fluxo produtivo dos panificados, desde suas matérias-primas de produção até a chegada do produto final na mesa do consumidor.

Como defende Ploeg (2008), a produção via agroindústria familiar é um contraponto aos impérios alimentares, sendo uma alternativa produtiva que questiona a produção convencional como racionalidade predominante e fortalece a participação da agricultura 
familiar, desenvolvendo a produção de forma descentralizada, promovendo a autonomia dos agricultores e a formação de ciclos curtos de produção e comercialização.

Dentro desta perspectiva, o fluxo de produção dos panificados demonstra uma produção de pequena escala, que atende a demanda local (Município), porém depende, também, de matérias primas que não foram, necessariamente, produzidos na região.

$\mathrm{O}$ atendimento aos programas governamentais (PAA, PNAE) proporcionam uma renda fixa à agroindústria. No entanto, elas pretendem alcançar mais os mercados formais da cidade e ampliar seu atendimento na feira. Isso requer o cumprimento de pré-requisitos para alcançar certos patamares de qualidade - que são ditados pelas grandes empresas agroalimentares, junto com a vigilância sanitária. Porém, possuem aspectos a seu favor, visto que são alimentos feitos, em partes, com produtos dos próprios agricultores associados (leite, ovos, banha de porco) e por serem de uma agroindústria artesanal, visto que os consumidores estão valorizando atualmente este mercado de cooperativas e produtos artesanais oriundos do espaço rural. É neste contexto que a agroindústria tende a ganhar novos consumidores.

Em suma, a agroindústria tem como diferencial a produção artesanal com produtos do pequeno agricultor cooperativado. Atualmente parte do consumidor citadino está procurando para consumir esse tipo de produto, valorizando os conhecimentos e a cultura tradicional. Neste contexto o quesito de qualidade foi revertido, ou seja, "a qualidade do alimento é, como vimos, associada mais à produção artesanal do que à industrial” (Wilkinson 2002, p.159). Deve-se ter cautela na busca por ampliação no atendimento ao mercado através da valorização dos recursos e conhecimentos tradicionais, segundo Wilkinson, para não haver desestabilização:

\footnotetext{
“O reconhecimento por parte do consumidor/cidadão dos valores associados à pequena produção (sejam sociais, culturais ou políticos) e as iniciativas para transformar esses em valores de mercado trazem ameaças de diversas ordens. Toda valorização, mesmo no caso de comércio justo, passa pela promoção de mudanças e investimentos que podem ter um impacto desestabilizador, seja internamente ao grupo em questão, seja em suas relações com a comunidade mais ampla." (WILKINSON, 2003, p. 63-64).
}

Assim, ao procurar ampliar o mercado, a agroindústria analisada não pode perder os valores tradicionais, que haja investimento, porém que não desestabilize a agroindústria, os membros e a dinâmica de produção, para não afetar a relação com o consumidor.

\section{Conclusões}

A consolidação da agroindústria rural é uma estratégia que ganha destaque no espaço rural entre agricultores familiares. Atividade que possui sua herança no processo de 
conservação e transformação colonial de alimentos, a qual tem sido desenvolvida como uma forma de integração e fortalecimento da agricultura familiar. O presente trabalho mostrou que a atividade de agroindustrialização atua como uma estratégia fundamental para reprodução dos agricultores familiares na medida em que oportuniza uma participação efetiva na comercialização dos seus produtos em circuitos locais e oportunizam melhor qualidade de vida as famílias envolvidas.

O presente estudo buscou analisar a agroindústria enquanto uma atividade estratégica para o fortalecimento das famílias envolvidas em termos de agregação de valor em seus produtos e acesso a mercados alternativos. Isso pode ser percebido na agroindústria estudada (Delícias do Campo), que se consolidou a partir do empenho e da ação coletiva entre as mulheres da comunidade rural Vasco da Gama, deixando de produzir informalmente os panificados em suas casas. $\mathrm{O}$ apoio da esfera pública municipal foi fundamental para a consolidação da atividade. A criação da agroindústria estudada contribuiu para a permanência das famílias no espaço rural, ampliando sua renda e propiciando melhor qualidade de vida na comunidade, como foi apontado pelas entrevistadas. A participação da agroindústria de panificados em um circuito local facilitou o acesso alternativo aos mercados por meio das vendas diretas ao consumidor, das feiras livres na associação da comunidade assim como venda para mercados institucionais.

Em suma, este estudo reafirma o potencial da agroindustrialização na agricultura familiar enquanto uma atividade que exerce um papel estratégico para o desenvolvimento rural local.

\section{Referências}

ABRAMOVAY, R. O Futuro das Populações Rurais. Porto Alegre, Ed. UFRGS, 2003. CENSO AGROPECUÁRIO IBGE (2006). Disponível em: <http://www.ibge.gov.br> Acesso em: $10 / 04 / 2015$

MALUF, R. S. Mercados Agroalimentares e a Agricultura Familiar no Brasil: agregação de valor, cadeias integradas e circuitos regionais. Ensaios FEE. Porto Alegre, v. 25, n. 1, p. 299322,2004 ISSN 1980-2668.

Disponível em: http://revistas.fee.tche.br/index.php/ensaios/issue/view/116. Acesso em: 15 de maio de 2016.

MIOR, L. C. Agricultura familiar, agroindústria e desenvolvimento territorial. COLÓQUIO INTERNACIONAL DE DESENVOLVIMENTO RURAL SUSTENTÁVEL. [UFSC], 2007, Florianópolis, Santa Catarina.

PMFI - Prefeitura do Município de Foz do Iguaçu, Secretaria Municipal de Administração / Departamento de Informações Institucionais. Dados Socioeconómicos de Foz do Iguaçu 2010. Disponível em: http://www.fozdoiguacu.pr.gov.br/Portal. Acesso em 20 de maio. 2015. 
PREZOTTO, L. L. Uma concepção de agroindústria rural de pequeno porte. Revista de Ciências Humanas. Florianópolis.v.31 n. 31, p.133-154, abril 2002. ISSN 2178-4582. Disponível em: https://periodicos.ufsc.br/index.php/revistacfh/issue/view/1092. Acesso em: 15 de maio de 2016.

WESZ JUNIOR, V. J. As novas configurações no meio rural: uma análise a partir das propriedades com agroindústria familiar no Brasil. In: SEMINARIO INTERNACIONAL DE DESARROLO RURAL, VI, 2008, Bogotá, Colômbia.

WILKINSON, J. Mercados, redes e valores: o novo mundo da agricultura familiar. Porto Alegre: UFRGS, 2008. 